\title{
The Principles and Practices of Supervision That Supports the Development of Inclusive Teacherhood
}

\author{
Sanna Alila ${ }^{1}$, Satu Uusiautti ${ }^{2} \&$ Kaarina Määttä ${ }^{2}$ \\ ${ }^{1}$ Valteri Centre for Learning and Consulting, Valteri, Finland \\ ${ }^{2}$ University of Lapland, Rovaniemi, Finland \\ Correspondence: Sanna Alila, Tilustie 4 D 1, 90650 Oulu, Finland. Tel: 358-40-749-7262. E-mail: \\ Sanna.Alila@tervavayla.fi
}

Received: June 1, 2016

Accepted: June 28, 2016

Online Published: July 20, 2016

doi:10.5539/jel.v5n3p297

URL: http://dx.doi.org/10.5539/jel.v5n3p297

\begin{abstract}
In this study, the purpose was to study what kind of supervision supports inclusive teacherhood the best. Inclusive teacherhood means a teacher's professional development and the school culture's change toward participatory school for all students. The study investigated the perceptions of supervisors with a teaching background. This was a qualitative research in which the data were obtained using the focus-group interview method. The interviews were conducted in five places in Finland. The analysis involved a combination of phenomenography, particularly the application called the variation theory, and the classic analysis of the focus-group research method. According to the findings, supervision that supports inclusive teacherhood can be viewed from two wide perspectives that represent its special features. They are the principles of supervision and the practical execution and special methods of supervision that differ from other mentoring forms. The principles of supervision are awareness of similar methods, careful planning of supervision, regularity, and long-term duration. The special practices of supervision are varied methods, attention to the supervisees' needs, and appreciation of the supervision process. At its best, supervision supports inclusive teacherhood by supporting and empowering teachers' in their work.
\end{abstract}

Keywords: supervision, inclusive teacherhood, supervisor with a teaching background, focus group interview

\section{Introduction}

Supervision has an established position as a well-known and widely-applied method in health care and nursing internationally (e.g., Brunero \& Stein-Parbury, 2008; Milne \& James, 2002). It has long roots in education and teaching, too, although the method has been less used. In Finland, supervision has been used for supporting teachers' professional growth and research for several decades (Alila, 2014; Alila, Määttä, \& Uusiautti, 2015). At the moment, the teacher's profession has become increasingly versatile due to ongoing societal changes and variety in the student groups, and therefore, the support provided by supervision is likely to become quite necessary. Especially, the enhancement of inclusion requires the adaptation of new kinds of thinking, attitudes, and methods from teachers (Ainscow, 2005).

This study focuses on teachers' development toward inclusive teaching approaches. Inclusion means education that is based on the idea of students' equal participation (Hulgin \& Drake, 2011). Equal opportunities within a heterogeneous group mean that all students get support in their physical, cognitive, emotional, and moral development within a safe, healthy, and intellectually developing environment (Lakkala, Uusiautti, \& Määttä, 2014). Inclusive teaching requires a flexible curriculum that notices the needs of various learners, accessible school buildings and premises, segregated teaching and evaluation, and teaching staff who has proper education about and abilities to implement inclusive practices (Lakkala \& Määttä, 2011; Symeonidou \& Phtiaka, 2009). In the context of inclusion, the Universal Design for Instruction (UDI) is an approach to teach all students, and it includes the predictive planning and usage of inclusive teaching strategies (McGuire, Scott, \& Shaw, 2006; Samuels, 2007).

Today's, learning communities are developed through professional collaboration, reflection, and empowering methods (Shepherd \& Hasazi, 2009). Research on supervision is still relatively scarce and more information about its benefits and realization is needed in the field. This study focused on supervisors' perceptions on the 
kind of supervision that supports the development of inclusive teacherhood the best. The purpose was to define by interviewing supervisors with a teaching background what kind of support the development of inclusive teachers. Their viewpoints provide important practical information about the nature and principles of supervision.

\section{Supervision in the Field of Education}

Supervision is based on various theoretical viewpoints, and therefore, its definition is still somewhat changing (Milne, 2007). It has influences from experiential learning (Milne \& James, 2002), constructivism (Ibrahim, 2013), team learning (Gillespie, 2012), and the principle of life-long learning. Likewise, the practices of supervision are manifold, especially in the field of education and teaching (cf., Falender, Burnes, \& Ellis, 2012). The supervision has some similar features with its close concepts such as guidance offered for novices teachers in their professional growth (Hobson, Ashby, Malderez, \& Tomlinson, 2009; Sundli, 2007); coaching (McLean \& Hudson, 2012) referring to a supervision relationship where the coach attempts to support the client's work-related choices; process consultation and consulting (Lambrechts, Grieten, Bouwen, \& Corthouts, 2009); and mentoring (e.g., Alila, 2014).

The most central methods of supervision are reflection and dialogue (Löfmark, Morberg, Öhlund, \& Ilicki, 2009). The supervisee's reflection and progress are supported by leaning of experiences of success and goal-setting (McCurdy, 2006; Stark, Frels, \& Garza, 2011). Supervision can also include drama-based methods (Denver \& Shiflett, 2011; Edwards, 2010). In an efficient supervision, tasks and goals are clearly defined and the supervisor pays attention to interaction and relationships between supervisees (Ladany, Mori, \& Mehr, 2013). A functional group supervision necessitates that the supervisor and supervisees are committed to communal learning (Henderson, 2009) and change (Hanna, 2011).

Supervision in teaching also leans on collaboration, reflection, and dialogue (Pattison, 2010) as it aims at a more profound understanding of a teacher's multidimensional role and teacher identity (Paliokosta \& Blandford, 2010). In the supervision of teachers, reflection means learning about the practical work, developing one's professional skills and teaching practices through a collaborative discussion (Carroll, 2010; Clouder \& Sellars, 2004; Hobson, Ashby, Malderez, \& Tomlinson, 2009; see also Sundli, 2007). This is especially important to the development of inclusive teacherhood, because the approach requires profound understanding about the nature of inclusion and teachers' ability to reflect on their personal teaching styles, practices, and teacherhood.

While teachers' work has fundamentally changed during the shift toward inclusion (Potmesilova, Potmesil, \& Roubalova, 2013), supervision has not yet gained an established position in the field of teaching and education. The purpose of this study is to show that supervision is an efficient support method that aims at developing teachers' expertise and abilities to embrace the inclusive teacherhood in their everyday work practices and in teacher identities in general (cf., Goodman, Brady, Duffy, Scott, \& Pollard, 2008; Luke, Ellis, \& Bernard, 2011). Supervision is needed to help teachers to cope with the increasing challenges in teachers' work.

\section{Method}

The purpose of this study is to describe what kind of supervision supports inclusive teacherhood according to supervisors with a teaching background. The following research questions were set for this study:

According to supervisors with a teaching background, what are the special features of supervision that supports the development of inclusive teacherhood and what is the supervision like?

The qualitative study approach was employed in this research. To answer the research question, the focus group interview method was chosen as the data collection method. The methodological approach represents phenomenography as it studied human beings' different ways of experiencing, conceptualizing, and understandinh the surrounding world and its phenomena (Marton, 1988). In addition, the research is connected with the variation theory of phenomenography because the other purpose was to analyze the dimension of variation within the phenomenon under investigation and to compare various viewpoints about it (Dahlin, 2007).

Focus group interviews were done in the spring of 2010. Eleven supervisors with a teaching background and from five cities in Finland were selected as the research participants. The criteria of selection were that they had been supervising at least for one year and that they were members of the Finnish Supervisors' Association. This association accepts as its members only persons, who have completed a long-term mentoring education. The research participants were women aged from 35 to 65 years.

A focus group interview is a method for discussing a topic in a group, and the discussion is led by the interviewer (Morgan, 2008). In this study, the focus group received nine questions to discuss. The purpose of the 
questions were to analyze together how supervision supports inclusive teacherhood. The main targets of discussions focused on the most suitable methods and resources of supervision that aims at supporting inclusive teacherhood. The supervisors were also asked to discuss what a suitable theoretical framework to supervision would be and what kinds of needs can be met with supervision. Focus group interviews have increased interest in many fields of research as they provide a functional way of sharing understanding about themes that have been less studied previously (Hesse-Biber \& Leavy, 2011; Stewart, Shamdasani, \& Rook, 2007).

When analyzing the data gathered by focus group interviews, themes that emerge in all or several groups and that are mentioned by many persons within one group are the most important ones (Hesse-Biber \& Leavy, 2011). In this study, the classic analyzing principles of focus group interviews were followed systematically (Krueger \& Casey, 2009).

The core of classic focus group interview analysis happens by cutting, categorization, and organization through comparisons and juxtapositions one interview question at a time (Krueger \& Casey, 2009). Each answer to a question is read and compared in order to find if the same theme or issue has been mentioned earlier. Similar issues are thus combined together and together they form a category. The analyzing process was long and laborious, and during it, the categories were re-organized and even re-created several times. Eventually, all answers found their places in categories that are here introduced as the themes within the main results. Indeed, another purpose of the analysis was to find the so-called main thoughts in the data. It refers to a mutual understanding about a theme among the majority of research participants (Vaughn, Schumm, \& Sinagub, 1996). In this study, the main results are organized into themes that represent the mutual understanding among the supervisers about these categories in the data.

In the results section, themes in these two main results categories are introduced by including quotes from the focus group interviews. The codes consist of numbers and letters. The number after the letter $\mathrm{K}$ refers to the ordinal number of the quote in the data. The number placed after comma stands for the page the quote can be found in the data transcript.

The reliability of this study can be evaluated from many points of view. Dr. Alila who was the head researcher of this study is a supervisor with teaching background herself, and therefore, her position is not totally objective. Obviously, she has a positive stand and experience about supervision and its significance to the development of inclusive teacherhood. This might have influenced on the way the results are interpreted. However, the personal viewpoint to and experience of the research theme also means immediate experience and profound understanding about the phenomenon. To improve the reliability of analysis, the findings and conclusions were discussed with the research group. In addition, the purpose was to bring out the supervisors' voices when reporting about the findings. This was also to improve reliability as the experts from data illustrate how the themes were brought out and discussed by the research participants.

As the number of research participants was small, the study could even be defined as a mini focus group research (Krueger \& Casey, 2009). However, the size of the group is also justifiable because these people present a marginal group based on their expertise and supervision experience in Finland. The interviewees also showed a positive attitude to supervision, and its possibilities to support the development of inclusive teacherhood were, thus, seen very high. Their versatile experiences provided a profound discussion about the support supervison can provide to the adaptation of inclusion in schools. The way the supervisees had experienced supervision was not studied in this research, but it would make a good add and presents a need for further research.

\section{Results}

The findings are organized according to two main results categories that are the principles of supervision and practical execution and special features of supervision when compared to other mentoring methods. The principles of supervision are awareness of similar methods, careful planning of supervision, regularity, and long-term duration. The special practices of supervision are varied methods, attention to the supervisees' needs, and appreciation of the supervision process.

\subsection{The Principles of Supervision}

The principles of supervision could be categorized into three special features. The first one was the awareness of similar methods. Supervisors considered it important that the supervisors were able to guide teachers to acquire right kind of support. They realized that supervision could not respond to all needs and situations but sometimes other methods of support could serve teachers the best.

k324,28-29 And similarly, along the road, you can ask whether you should change it [the method of support] into something else... 
k298,26 You kind of have to transmit those issues or the school practices to a new teacher. So these situations would be something that mentoring, for example, could fit.

In the data, the supervisors discussed widely the usability of supervision and its relative methods. For example, mentoring is very useful when you have to teach the school practices to a new teacher. Short-term periods that aim at fast solutions resemble merely coaching instead of supervision. In all cases, participation in supervision has to be voluntary even if it was the only available method of support.

The supervisors with a teaching background expressed that, according to their understanding, supervision that supports the development of inclusive teacherhood, should be sufficiently wide of its theoretical framework.

$k 606,56$ The fact is that whatever the framework was does not matter so much.

k610,56 If I am like...strictly representing a certain viewpoint, I won't necessarily be able to hear what someone says. As if I had one kind of headphones and just one kind of messages come through.

The same kind of broadmindedness as inclusive teacherhood necessitates in teachers, supervisors need when they guide teachers. They also need wide perspectives in their work. General humanity and appreciative atmosphere as well as hearing the supervisee's needs are crucial elements of supervision.

The supervision process may start with a couple of initial meetings during which the supervisor and supervisees can test how compatible their framework and methods are before making the decision about the continuation of the supervision process. In this stage, such theoretical knowledge that helps understanding students' growth, the group, school organization, and leadership practices is essential. The supervisor has to be on first names terms with the philosophy of inclusion and be aware of the opposition against it. Therefore, when supporting the development of inclusive teacherhood, the supervisor has to, every now and then, step aside so that the teachers can construct their own practical theory and methods.

In addition, the question of whether supervision of the development of inclusive teacherhood should be arranged as individual, group, or work unit guidance may be decided later. The supervisors emphasized that the decision of the supervision format should be open until the best way of supervising is decided.

$k 528,48$ I think they all are; in my opinion, they all have a chance, so that I would not exclude any of them.

k509,46 If you think that your work community and groups and the community again, so that it really could be. Or why not individual supervision too if someone feels he or she needs that.

The other principle emphasized the careful planning and goal-orientation when supporting the development of inclusive teacherhood. Supervisors with a teaching background considered it important to set goals for supervision and working strictly in this direction.

$k 26,8$...I have been thinking about the question of... what they need from supervision, what is that.

$k 730,69$...I think it would be important to have reasons for that. Because otherwise it can arouse doubts 'what supervision' to those who are not used to having it.

According to the data, it is important to set clear goals to supervision and think about the reasons why this particular supervision process started. The supervisor and supervisees have to be aware of the usability and opportunities of using supervision in educational organizations.

The third principle of supervision according to the participants of this study was regularity and long duration of supervision. They wanted to emphasize that supervision that aims at development needs time and sufficient resources.

$k 479,44$ This kind of growth process takes resources and it takes time... if the teacher pursues something like this and wants to be supervised, it takes time, requires many supervision times...

k418,39 At least it has to be... regular and sufficient for its duration. Because, indeed, the teacher needs support for the whole time, from the beginning to the end of the supervision period.

Inclusive teacherhood and the common understanding about the nature of inclusion does not develop at once. Therefore, supervision that supports the development has to be long term (e.g., two years) as well, so that some development actually happens. The beginning takes time due to initial resistance and orientation period. The supervision should be arranged at least every four weeks so that the process goes on naturally. A long-term supervision makes the reflection process possible and the supervisees notice who their thinking changes. The realization of one's own learning process is the empowering factor at work and during the supervision process. 
The requirements of regularity and long-term supervision necessitate resources to supervision as such but also an opportunity to receive supervision during work hours, which is not easily arranged in teachers' work. The participants suggested that supervision could be considered optional to in-service training or teachers' shared planning time, or be arranged when students have their off-school work familiarization week in workplaces. In addition, school holidays and periods have to be taken into account when planning supervision.

\subsection{The Practical Execution and Special Features of Supervision}

Supervision that supports the development of inclusive teacherhood could be seen as three sets of practices in the supervisor interviews. The first central factor in the supervision was the use of a variety of methods. Diversity of supervision methods was reported to meet the versatile needs of teaching.

k519,47 I would say that we should use all means available.

$k 487,45$...If you thinkt that the group has all kinds of students, so is it even possible not to use varied methods in supervision.

k411,37 ...those methods...it would be important that the supervisor had a full bag of them.

Supervisors have to be ready to use versatile methods in supervision. Inclusive teacherhood is a multidimensional phenomenon and its development necessitates various methods from supervision. Supervisors with a teaching background reported that they favor functional, solution-centered, and visual methods and group discussions in supervision. Experience of variety in supervision can transform into variety in teaching.

The second practical perspective in supervision was to define the supervisees' needs. However, at the same time, it was considered important to pay attention to the work culture in the community as a whole too.

k359,33 I depends on a person, too, a little; what kind of supervision he or she wants... I would claim that what they are ready and capable of receiving... and what they want and what benefits them.

$k 397,36$ It starts with all these personalities, and we start to develop it through searching and disovering it together.

$k 365,33$ You just have to keep your antennae up to know what the issue is and what the feeling is at all times.

The supervisor's expertise is tested when finding the balance between supervisees' needs and their work culture. The choice of supervision methods depends on the stage of the process of supervision and development of inclusive teacherhood as well. Supervision starts from the personalities and familiarization so that the common direction can be found to approach the shared learning and change. Likewise, the teachers' personal goals they have set for supervision and its contents direct supervisors when they construct a suggestion of supervision method.

When supervising individual teachers, their work community has to be noticed as well. According to the supervisors, this is the only way of developing the whole school culture toward inclusion.

$k 540,50$ I stick to that immediately. So I would start from the work community. If you try to build this idea inside the school, it would be supervision of the work community.

k514,47 Here of course that supervision of the work community. Working with the work community could be something you could think about.

k507,46 ...if you are building an inclusive school, you would need also to supervise the whole work community depending on the phase it is. Whether it is starting inclusive action or much further. That tells you pretty much, the phase they are in. When you start something new, you need the whole community.

Relationships, coping, and common rules are often the themes of supervision. When supporting the development of inclusive teacherhood, this would mean, for example, that the supervision group consisted of people who actually work together at school.

The third practical framework for supervision was to strengthen the appreciation of the supervision process. In the field of teaching, supervision is still relatively minimal due to its unavailability and difficulties in arranging it. Therefore, teachers' awareness of the meaning and opportunities of supervision is still scarce.

The supervisors with a teaching background considered it important that the supervision provided confidential, mental space to discuss teachers' situations at work.

k233,21 In your everyday work, when you are attached to it fully so that you cannot pay attention to your action without the mirror coming from outside. 
k238,21 The teacher's work is quite preset. You have those lessons and then try to find time for all other activities, time and place for meeting parents. Then the supervision is there; how to protect it from all that and make it a peaceful work situation.

k163,17 ... and calming down and interrupting the hectic work so that you can sit down and think. I get this kind of feedback a lot.

Analyzing teachers' work during school days is not possible. Supervision can provide time, space, and support that enables the reflection of teachers' own practices and professional development. Therefore, on the one hand, supervision can support reflection, and on the other hand, provide a confidential space to analyze even difficult situations at work.

Supervision can provide time to develop inclusive school and discuss challenges and difficulties occurring in teaching.

$k 761,72$ I think we can work in a totally different mood if we have the chance sometimes... to see these issues... think about them at the time reserved for it.

The supervisors' common conception was that, for many reasons, teachers find it difficult to ask for supervision and start the supervision process. The reasons were the difficulties of arranging supervision in practice as well as reserved idea of supervision as a method to develop their professional expertise.

k820,79-80 ...because certainly there are teachers who have the experience that this kind of discussion is waste of time, blathering...

k133,15 The sort of intellectual strength [in teachers]. It is difficult not to be like "I know it better".

$k 243,22$... and is it so difficult for teachers to be in a position in which they could be learners and such.

Turning from a teacher's strong professional sense of control into a learner's role, which is aspired-at least to some extent-in supervision, may feel difficult or minimal. Authenticity and being honestly oneself in regard of one's professional identity demands plenty of time in the supervision process from anyone.

\section{Conclusions}

We have illustrated the contribution of the study in Figure 1. The first two sections describe the main findings of the principles and practices of supervision. According to the two-dimensional analysis of principles and practices, it could be concluded that they would lead to certain desirable outcomes that are presented in the third section.

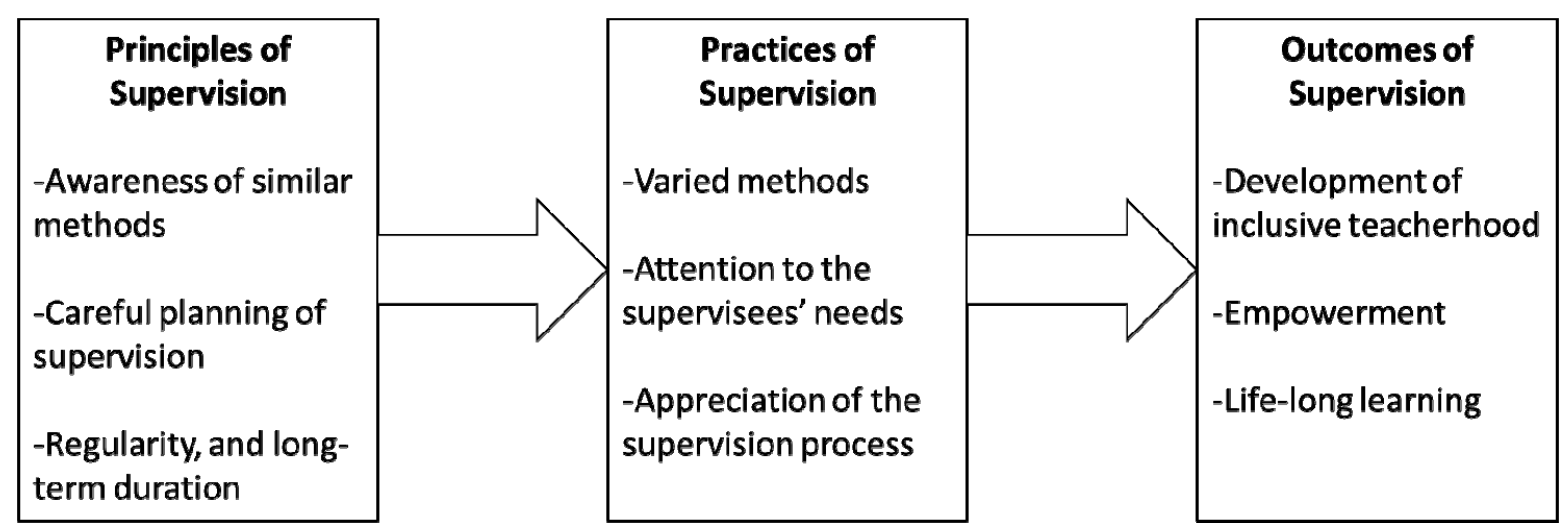

Figure 1. The supervision process of the development of inclusive teacherhood (designed by Uusiautti)

In sum, supervision can be used for developing inclusive teacherhood in teachers both individually and communally in the school's work community. The core elements of supervision are goal-orientation, confidentiality, and the supervisor's professionalism. At its best, supervision can form a learning environment of inclusive teacherhood, in which the stability, regularity, and continuity of supervision are the key. These elements appear somewhat general and adjustable to various supervision situations in the field of education. However, the specific viewpoint in this study was in the development of inclusive teacherhood, and therefore, the descriptions of methods used in supervision can help schools to apply supervision for these developmental purposes. In addition, as the study showed, supervision can inspire inclusive practices in teaching, as they 
encourage teachers to use a wide range of teaching methods and to understand the importance of flexibility in teaching arrangement in practice.

The ideal outcomes of supervision are the actual development of inclusive teacherhood, which can lead to empowerment as well. As the findings also showed, teachers had to adopt the role of a learner in the process, and therefore, supervision process also requires the ability to life-long learning.

Supervision may serve as a kind of a learning laboratory in which participants can reflect on the new practices with each other. Leaders and managers can participate in supervision that aims at developing their leadership practices alone or in a group that consists of their leader colleagues. In all, leaders and managers make an important part of the supervision process in a work community. They can participate in supervision either actively or the supervisor can report the progress of supervision process according to the supervision agreement and as agreed with the group.

The field of teaching and education has plenty of phenomena that cannot be solved at once but that have to be reflected from several perspectives. The solutions become the better, the more they can be prepared through a process. Supervision makes it possible to approach these issues with time. Especially in schools, the workdays have busy and tight schedules which makes group work and group discussions impossible. Therefore, teachers' professional development and joint school development necessitate time reserved just for them. Actually the report by Eurydice (2013) points out that teachers' continuous professional development has become more and more important lately. Several countries in the European Union have orders about it in laws or directions, while in some countries it is written in collective labor agreements (Eurydice Report, 2013; see also Takkula, 2016).

\section{Discussion}

Inclusive education calls for a change in school practices (Bourke, 2009), and, therefore, teachers must feel supported to develop toward inclusive teacherhood (Ainscow, 2008). Supervision can provide one functional answer to these demands (Potmesilova, Potmesil, \& Roubalova, 2013). The Universal Design for Learning (UDL) provides viewpoints to the development of supervision. It presents the guidelines of changing the curriculum to be more flexible and suitable to all students (Hitchcock \& Stahl, 2003), which demands new attitudes and methods from teachers as well. The purpose of UDL is to provide choices (Lancaster, 2011). UDL considers it as an important, fundamental approach in teaching, and perceives its benefits students and teachers in special and general education (Jiménez, Graf, \& Rose, 2007).

The fact is that the increase in students' participation especially depends on teachers' educational choices of how they implement teaching methods and what kinds of teaching ideologies they follow in teaching (Shevlin, 2010). Actually, teaching practices suitable for students who need special support have proven to be suitable for other students too (Spaulding \& Flanagan, 2012). In all, the development of inclusion in education renews teaching and related values, beliefs, and attitudes (Singal, 2008).

Supervision is not widely used in teaching at the moment, and therefore, studies that illustrate the importance and implementation of supervision are greatly needed. The findings of this study are to provide some answers to this need. Teachers' participation in supervision is currently voluntary, but it seems that teachers, who participate in it, see to engage in the supervision process well (Alila, Määttä, \& Uusiautti, 2015). Interaction with colleagues in the learning work community and the opportunity to see colleagues' professional development strengthen teachers' meaningful life-long learning (Alila, 2014; Hawkins \& Shohet, 2012). According to supervision studies, teacher have been able to change their beliefs and raise their awareness when they have been given the opportunity to reflect on issues related to teaching and learning (Jordan, Schwartz, \& McGhie-Richmond, 2009). Teachers cannot mold all factors in the learning environment, but they can influence attitudes, attention to segregated methods, and their awareness of students' reactions (Abbott, 2011).

This study also showed that it is necessary to reflect on the supervision practices clearly. When it comes to teachers, the role of a learner may be difficult to adopt, and therefore, the supervision style should be adjusted to the supervisee's personal learning style — or it can challenge the supervisee's style and thus ignite wider development in him or her (Bernard, Clingerman, \& Gilbride, 2011). In the field of education and teaching, it would be important to learn to see supervision as a natural part of work and as a functional method. Supervision is considered a taboo and teachers tend to feel need to explain and make up reasons for their participation in supervision. These are preconceptions that cannot be omitted without open-minded participation and active distribution of knowledge about supervision in teachers' work. This study wanted to contribute to this emerging field of research and academic discussion. Still, not only awareness of supervision has to expand but also 
supervision itself has to develop so that it can better fulfill teachers' developmental needs in their rapidly changing work (see also Connor \& Pokora, 2012; de Janasz \& Sullivan, 2004; Hawkins \& Shohet, 2012).

\section{References}

Abbott, C. (2011). Aiming for inclusion: Removing barriers and building bridges. In J. Dillon, \& M. Maguire (Eds.), Becoming a teacher. Issues in secondary education (pp. 236-248). Maidenhead: Open University Press.

Ainscow, M. (2008). Teaching for diversity: The next big challenge. In F. Connelly, M. He, \& J. Phillion (Eds.), The Sage handbook of curriculum and instruction (pp. 240-259). Los Angeles, CA: SAGE. http://dx.doi.org/10.4135/9781412976572.n12

Ainscow, M. (2005). Developing inclusive education systems: What are the levers for change? Journal of Educational Change, 6(2), 109-124. http://dx.doi.org/10.1007/s10833-005-1298-4

Alila, S. (2014). "Työnohjaus auttaa löytämään omia vahvuuksia ja ... toimintakulttuurin luomisessa." Työnohjaus inklusiivisen opettajuuden tukena ["Supervision helps you to find our strengths and ... to create the work culture." Supervision as the support for inclusive teacherhood] (PhD Diss). University of Lapland, Rovaniemi, Finland.

Alila, S., Määttä, K., \& Uusiautti, S. (2015). How does supervision support inclusive teacherhood? International Electronic Journal of Elementary Education, 8(3), 351-362.

Bernard, J., Clingerman, T., \& Gilbride, D. (2011). Personality type and clinical supervision interventions. Counselor Education \& Supervision, 50(3), 154-170. http://dx.doi.org/10.1002/j.1556-6978.2011.tb00117.x

Bourke, P. (2009). Professional development and teacher aides in inclusive education contexts: Where to from here? International Journal of Inclusive Education, 13(8), 817-827. http://dx.doi.org/10.1080/13603110802128588

Brunero, S., \& Stein-Parbury, J. (2008). The effectiveness of clinical supervision in nursing: An evidenced based literature review. Australian Journal of Advanced Nursing, 25(3), 86-94.

Carroll, M. (2010). Supervision: Critical reflection for transformational learning (Part 2). The Clinical Supervisor, 29(1), 1-19. http://dx.doi.org/10.1080/07325221003730301

Clouder, L., \& Sellars, J. (2004). Reflective practice and clinical supervision: An interprofessional perspective. Journal of Advanced Nursing, 46(3), 262-269. http://dx.doi.org/10.1111/j.1365-2648.2004.02986.x

Connor, M., \& Pokora, J. (2012). Coaching and mentoring at work. Developing effective practice (2nd ed.). Maidenhead: Open University Press.

Dahlin, B. (2007). Enriching the theoretical horizons of phenomenography, variation theory and learning studies. $\begin{array}{llll}\text { Scandinavian Journal of Educational research, } & \text { 51(4), 327-346. }\end{array}$ http://dx.doi.org/10.1080/00313830701485437

de Janasz, S. D., \& Sullivan, S. E. (2004). Multiple mentoring in academe: Developing the professorial network. Journal of Vocational Behavior, 64, 263-283. http://dx.doi.org/10.1016/j.jvb.2002.07.001

Denver, S., \& Shiflett, C. (2011). Art-based supervision techniques. The Clinical Supervisor, 30(2), 257-276. http://dx.doi.org/10.1080/07325223.2011.619456

Edwards, D. (2010). Play and metaphor in clinical supervision: Keeping creativity alive. The Arts in Psychotherapy, 37(3), 248-254. http://dx.doi.org/10.1016/j.aip.2010.04.011

Eurydice report. (2013). Key data on teachers and school leaders in Europe. Education and training. European Commission. http://eacea.ec.europa.eu/education/eurydice/documents/key_data_series/151EN.pdf

Falender, C., Burnes, T., \& Ellis, M. (2012). Multicultural clinical supervision and benchmarks: Empirical support informing practise and supervisor training. The Counseling Psychologist, 41(1), 8-27. http://dx.doi.org/10.1177/0011000012438417

Gillespie, J. (2012). Teaching Note: Enhancing social work education through team-based learning. Journal of Social Work Education, 48(2), 377-387. http://dx.doi.org/10.5175/JSWE.2012.200900014 
Goodman, I., Brady, M., Duffy, M., Scott, J., \& Pollard, N. (2008). The effects of "bug-in-ear" supervision on special education teachers' delivery of learn units. Focus on Autism and Other Developmental Disabilities, 23(4), 207-216. http://dx.doi.org/10.1177/1088357608324713

Hanna, F. (2011). Freedom: Toward an integration of the counseling profession. Counselor Education \& Supervision, 50(6), 362-385. http://dx.doi.org/10.1002/j.1556-6978.2011.tb01921.x

Hawkins, P., \& Shohet, R. (2012). Supervision in the helping professions (4th ed.). Maidenhead: Open University Press.

Henderson, P. (2009). Supervision training: Issues and approaches (Vol. 2). London: Karnac Books.

Hesse-Biber, S., \& Leavy, P. (2011). The practise of qualitative research (2nd ed.). Thousands Oaks, CA: SAGE.

Hitchcock, C., \& Stahl, S. (2003). Assistive technology, universal design, universal design for learning: Improved learning opportunities. Journal of Special Education Technology, 18(4), 45-52.

Hobson, A., Ashby, P., Malderez, A., \& Tomlinson, P. (2009). Mentoring beginning teachers: What we know and what we don't. Teaching and Teacher Education, 25(1), 207-216. http://dx.doi.org/10.1016/j.tate.2008.09.001

Hulgin, K., \& Drake, B. (2011). Inclusive education and the No child left behind act: Resisting entrenchment.

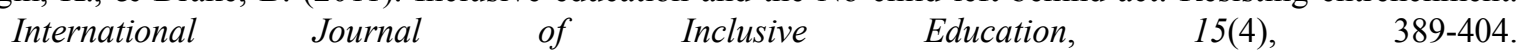
http://dx.doi.org/10.1080/13603110903030105

Ibrahim, A. (2013). Approaches to supervision of student teachers in one UAE teacher education program. Teaching and Teacher Education, 34, 38-45. http://dx.doi.org/10.1016/j.tate.2013.04.002

Jiménez, T., Graf, V., \& Rose, E. (2007). Gaining access to general education: The promise of universal design for learning. Issues in Teacher Education, 16(2), 41-54.

Jordan, A., Schwartz, E., \& McGhie-Richmond, D. (2009). Preparing teachers for inclusive classrooms. Teaching and Teacher Education, 25(4), 535-542. http://dx.doi.org/10.1016/j.tate.2009.02.010

Krueger, R., \& Casey, M. (2009). Focus groups. A practical guide for applied research (4th ed.). Thousands Oaks, CA: SAGE.

Ladany, N., Mori, Y., \& Mehr, K. (2013). Effective and ineffective supervision. The Counseling Psychologist, 41(1), 28-47. http://dx.doi.org/10.1177/0011000012442648

Lakkala, S., \& Määttä, K. (2011). Towards a theoretical model of inclusive teaching strategies-An action research in an inclusive elementary class. Global Journal of Human Social Science, 11(8), 31-40.

Lakkala, S., Uusiautti, S., \& Määttä, K. (2014). How to make the neigbourhood school a school for all? Finnish teachers' perceptions of educational reform aiming toward inclusion. Journal of research in Special Educational Needs.

Lambrechts, F., Grieten, S., Bouwen, R., \& Corthouts, F. (2009). Process consultation revisited. Taking a relational practice perspective. Journal of Applied Behavioral Science, 45(19), 39-58. http://dx.doi.org/10.1177/0021886308326563

Lancaster, P. (2011). Universal design for learning. Colleaques, 3(1), 1-3. Retrieved from $\mathrm{http}: / /$ scholarworks.gvsu.edu/cgi/viewcontent.cgi?article=1070\& context $=$ colleagues

Luke, M., Ellis, M., \& Bernard, J. (2011). School counselor supervisors' perceptions of the discrimination model

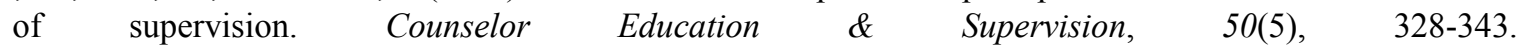
http://dx.doi.org/10.1002/j.1556-6978.2011.tb01919.x

Löfmark, A., Morberg, Å., Öhlund, L., \& Ilicki, J. (2009). Supervising mentors' lived esperience on supervision in teach, nursing, and social care education. A participation-oriented phenomenological study. Higher Education, 57(1), 107-123. http://dx.doi.org/10.1007/s10734-008-9135-3

Marton, F. (1988). Phenomenography. A research approach to investigating different understandings of reality. In R. Sherman, \& R. Webb (Eds.), Qualitative research in education. Focus and methods (pp. 141-161). London: Falmer-Press.

McCurdy, K. (2006). Adlerian supervision: A new perspective with a solution focus. Journal of Individual Psychology, 62(2), 141-153. 
McGuire, J., Scott, S., \& Shaw, S. (2006). Universal design and its applications in educational environments. Remedial and Special Education, 27(3), 166-175. http://dx.doi.org/10.1177/07419325060270030501

McLean, P., \& Hudson, F. (2012). Completely revised handbook of coaching: A developmental approach (2nd ed.). Somerset: Wiley.

Milne, D. (2007). An empirical definition of clinical supervision. British Journal of Clinical Psychology, 46(4), 437-447. http://dx.doi.org/10.1348/014466507X197415

Milne, D., \& James, I. (2002). The observed impact of training on competence in clinical supervision. British Journal of Clinical Psychology, 41(1), 55-72. http://dx.doi.org/10.1348/014466502163796

Morgan, D. (2008). The focus groups. In L. Given (Ed.), The Sage encyclopedia of qualitative research methods (pp. 353-355). Thousands Oaks, CA: SAGE.

Paliokosta, P., \& Blandford, S. (2010). Inclusion in school: A policy, ideology or lived experience? Similar findings in diverse school cultures. Support for Learning, 25(4), 179-186. http://dx.doi.org/10.1111/j.1467-9604.2010.01464.x

Pattison, S. (2010). Reaching out: A proactive process to include young people with learning disabilities in counselling in secondary schools in The UK. British Journal of Guidance \& Counselling, 38(3), 301-311. http://dx.doi.org/10.1080/03069885.2010.491849

Potmesilova, P., Potmesil, M., \& Roubalova, M. F. (2013). Supervision as a prevention and support teachers in inclusive education. Electronic Journal for Inclusive Education, 2(11), 1-12.

Samuels, C. (2007). "Universal design" concept pushed for education. Education Week, 27(10), 1-12.

Shepherd, K., \& Hasazi, S. (2009). Leadership for social justice and inclusion. In I. Florian (Ed.), The SAGE Handbook of special education (pp. 476-487). London: SAGE.

Shevlin, M. (2010). Count me in! Ideas for actively engaging students in inclusive classrooms. London: Jessica Kingsley Publishers.

Singal, N. (2008). Working towards inclusion: Reflections from the classroom. Teaching and Teacher Education, 24(6), 1516-1529. http://dx.doi.org/10.1016/j.tate.2008.01.008

Spaulding, I., \& Flanagan, J. (2012). Dis2ect. A framework for effective inclusive science instruction. Teaching Exceptional Children, 44(6), 6-14. http://dx.doi.org/10.1177/004005991204400601

Stark, M., Frels, R., \& Garza, Y. (2011). The use of sand-tray in solution-focused supervision. The Clinical Supervisor, 30(2), 277-290. http://dx.doi.org/10.1080/07325223.2011.621869

Stewart, D., Shamdasani, P., \& Rook, D. (2007). Focus groups. Theory and practice (2nd ed.). Thousands Oaks, CA: SAGE. http://dx.doi.org/10.4135/9781412991841

Sundli, L. (2007). Mentoring-A new mantra for education? Teaching and Teacher Education, 23(2), 201-214. http://dx.doi.org/10.1016/j.tate.2006.04.016

Symeonidou, S., \& Phtiaka, H. (2009). Using teachers' prior knowledge, attitudes and beliefs to develop in-service teacher education courses for inclusion. Teaching and Teacher Education, 25(4), 543-550. http://dx.doi.org/10.1016/j.tate.2009.02.001

Takkula, H. (2016, in press). Euroopan unionin opettajankoulutus-Millaisena sen näkevät EU-maiden opetusministerit ja Euroopan parlamentin koulutusvaliokunnan jäsenet? [Teacher training in the European Union-How do EU ministers of education and members of the educational parliament perceive it?] ( $\mathrm{PhD}$ Diss.). University of Lapland, Rovaniemi.

Vaughn, S., Schuman, J. S., \& Sinagub, J. (1996). Focus Group interviews in education and psychology. Thousand Oaks: SAGE. http://dx.doi.org/10.4135/9781452243641

\section{Copyrights}

Copyright for this article is retained by the author(s), with first publication rights granted to the journal.

This is an open-access article distributed under the terms and conditions of the Creative Commons Attribution license (http://creativecommons.org/licenses/by/3.0/). 